\title{
A organização da prática dos roteiros turísticos no turismo receptivo
}

\author{
TALita Almeida Fernandes ${ }^{1}$ \\ ALFRedo Rodrigues LeITE DA SILVA ${ }^{1}$ \\ FILIPE CABACINE LOPES MACHADO ${ }^{2}$
}

${ }^{1}$ Universidade Federal do Espírito SANTo (UFES) / Departamento de AdMinistração, Programa de Pós-GraduaçÃo EM AdMinistração, VITÓRIA - ES, BRASIL

${ }^{2}$ INSTITUTO FEDERAL do ESPÍRITO SANTO (IFES) / COORDENADORIA DO CURSO TÉCNICO EM AdMINISTRAÇÃO, LINHARES - ES, BRASIL

\begin{abstract}
Resumo
Nesta pesquisa, objetivou-se compreender o organizar da prática de roteiros turísticos a partir da epistemologia da prática de Theodore Schatzki. O estudo se baseou na epistemologia das práticas segundo Schatzki. Realizou-se uma pesquisa qualitativa que utilizou como procedimentos de coleta de dados: pesquisa documental, entrevistas informais e observações participantes. O tratamento dos dados ocorreu a partir de temas definidos a posteriori por meio da análise em espiral. Os resultados indicaram que a dinâmica do roteiro deve ser considerada durante toda a sua prática. Tal dinâmica é resultado de interações entre humanos e elementos materiais que, a partir da organização das práticas, podem ser transformadas de não turísticos a turísticos e promover alterações em toda a configuração da rede de práticas do turismo. Durante a prática do roteiro, humanos e materiais se organizaram e se transformaram em elementos turísticos, surgindo uma relação que só existe durante a prática do roteiro. Ademais, a prática do roteiro apresenta compartilhamentos que permitem lidar com o não compartilhamento, ao mesmo tempo que propicia que ele ocorra.
\end{abstract}

Palavras-chave: Teoria da prática. Epistemologia de Schatzki. Turismo como prática. Roteiros turísticos.

\section{The organization of the practice of tourist itineraries in receptive tourism}

\section{Abstract}

This research aimed to understand the organization of the practice of tourist itineraries based on Theodore Schatzki's epistemology of practice. For data collection, this qualitative research used documentary research, informal interviews, and participant observations. Data treatment occurred from themes defined a posteriori through spiral analysis. The findings indicate that the dynamics of the tourist itineraries should be considered throughout its practice. This dynamic is a result of interactions between humans and materials that, from organizational elements, can be transformed from non-tourist to tourist and promote changes throughout the configuration of the tourism network of practices. Tourist itineraries involve humans and materials organizing themselves and becoming tourist elements, creating a relationship that only exists while going through the itinerary. In addition, the tourist route presents sharing that addresses non-sharing, while allowing it to occur.

Keywords: Practice theory. Epistemology of Schatzki. Tourism as practice. Tourist itineraries.

\section{La organización de la práctica de los itinerarios turísticos en el turismo receptivo}

\section{Resumen}

El objetivo de esta investigación fue comprender la organización de la práctica de itinerarios turísticos desde la epistemología de la práctica de Schatzki. Se realizó una investigación cualitativa que utilizó como procedimientos de recolección de datos: investigación documental, entrevistas informales y observaciones participantes. Los datos se trataron a partir de temas definidos a posteriori por medio del análisis en espiral. Los resultados indican que la dinámica del itinerario debe ser considerada durante toda su práctica. Esta dinámica es el resultado de las interacciones entre humanos y elementos materiales que, a partir de la organización de las prácticas, pueden pasar de no turísticos a turísticos y promover cambios en toda la configuración de la red de prácticas del turismo. Durante la práctica del itinerario, humanos y materiales se organizaron y transformaron en elementos turísticos, surgiendo una relación que solo existe durante la práctica del itinerario. Además, la práctica del itinerario presenta comparticiones que permiten lidiar con el no compartir, al mismo tiempo que propicia que se lleve a cabo.

Palabras clave: Teoría de la práctica. Epistemología de Schatzki. Turismo como práctica. Itinerarios turísticos. 


\section{INTRODUÇÃO}

Discussões nos campos do turismo (E. Cohen \& S. A. Cohen, 2012) e dos estudos organizacionais (F. B. Meira \& M. B. V. Meira, 2007) têm reconhecido os impactos das mudanças contemporâneas no mundo e no processo de organizar. Ao mesmo tempo, a articulação das contribuições mútuas entre os dois campos tem sido defendida. Tal articulação é considerada um meio para tratar da complexidade que surge em virtude desses impactos nas organizações relacionadas com o turismo (Tomazzoni, Dorion \& Zottis, 2008). Neste artigo, faremos essa aproximação entre os dois campos ao abordarmos os roteiros turísticos.

Os roteiros turísticos têm sido estudados em duas grandes abordagens. Na primeira abordagem, tais roteiros são tratados como mapas prescritos a ser seguidos, e os estudos buscam compreender relações entre determinadas variáveis com influências sobre os roteiros (Li, Zhou \& Zhao, 2016; Stone, 2016). Na segunda, os roteiros são tratados como rotas experienciais, em estudos com maior foco no caráter epistemológico do turismo (Cisne \& Gastal, 2011). Nessa última abordagem, as preocupações se voltam para as interações cotidianas como parte do roteiro. Ao concordarmos com a relevância dessas preocupações, este estudo se aproxima dessa segunda abordagem, mas adota um caminho que não foi identificado em estudos anteriores sobre o tema.

A proposta aqui desenvolvida se baseia em contribuições de uma abordagem que faz parte das teorias da prática social (Schatzki, 2001, 2006), do campo do turismo (Bispo, 2016) e do campo dos estudos organizacionais (Czarniawska, 2008). Essas contribuições desenvolveram a ênfase no organizar com foco nas práticas - aqui diversos atores e aspectos materiais são elementos em interação, em um processo instável, sempre em andamento, em uma prática organizativa.

Portanto, além de se inserir nos estudos organizacionais, este artigo faz parte dos estudos no campo do turismo. Segundo Tribe (2010), esse campo é formado por duas grandes redes de estudo, a do negócio do turismo e da ciência social do turismo, além de outras redes com abordagens distintas, voltadas, por exemplo, para a teoria crítica. $O$ autor deixou claro que o campo do estudo do turismo não segue um paradigma unificado. Contudo, ao longo de sua trajetória, se estabeleceu nele o que F. B. Meira e M. B. V. Meira (2007) evidenciam como a aproximação entre o turismo, a economia e a administração. Para os autores, o primeiro se relaciona com aspectos tratados nos outros dois, como qualidade, competição, oferta, demanda, entre outros. Os autores ressaltam, ainda, que a produção do turismo pode ser, em parte, compreendida a partir das forças que a organizam em torno desses aspectos.

Para buscar essa compreensão, com foco nos roteiros, este artigo faz a aproximação entre o turismo e os estudos organizacionais. Assim como Tomazzoni et al. (2008), nos aproximamos dos estudos organizacionais para tratar do turismo, pois entendemos as organizações como marcadas pela complexidade envolvendo pessoas e relações entre diversas organizações. Para esses autores, esse fenômeno organizacional se amplia nas organizações que atuam no turismo. Isso ocorre porque elas são, basicamente, um conjunto complexo de interações entre múltiplas organizações e diversas pessoas, de maneira instável e temporária, com o envolvimento direto do próprio turista durante a produção voltada para lhe ofertar algo.

Essa visão se opõe aos estudos que tratam os processos organizacionais ligados ao turismo como algo previsível (Li et al., 2016; Stone, 2016), ignorando aspectos relevantes da sua dinâmica - por exemplo, a extensão na qual, mesmo quando planejado antecipadamente, "[...] o pacote ou roteiro turístico possui inúmeras situações imprevisíveis, pois as preferências e decisões de consumo se manifestam à medida que a viagem se desenvolve [...]" (Tomazzoni et al., 2008, p. 145).

O ato de ignorar essas situações é explicado por F. B. Meira e M. B. V. Meira (2007) quando revelam que a organização da indústria do turismo assume a previsibilidade para ofertar uma segurança concretizada em roteiros de viagens predefinidos, com base na disciplina do tempo, das direções para onde se deve olhar. A proposta deste artigo é penetrar na prática desses roteiros predefinidos, seguros e disciplinados e, pela via da prática, revelar uma dinâmica própria em seu organizar, que vai além dessa disciplina.

Dessa maneira, este artigo faz parte do movimento a partir do qual o campo do turismo se consolida como flexível e permeável, no qual diferentes abordagens têm base para coexistir (Tribe, 2010). A pluralidade atual do campo é influenciada por mudanças contemporâneas como o desenvolvimento tecnológico, a disseminação da comunicação e a globalização, que proporcionam constantes e intensas transformações e fragmentações envolvendo objetos, pessoas, tempo, espaço, entre muitos outros (E. Cohen \& S. A. Cohen, 2012). 
Segundo E. Cohen e S. A. Cohen (2012), essas movimentações se relacionaram com o surgimento de três novas abordagens nos estudos sobre turismo: a das mobilidades - voltada para as contínuas mobilidades contemporâneas, voluntárias ou não, tais como migração, ausência de residência fixa, múltiplas nacionalidades em suas relações com o turismo; a das performatividades - voltadas para o entrelaçamento de atos performativos recorrentes, como a admiração ou santificação que fazem parte de atrações turísticas, com foco em sua (re)produção, transformação e/ou crítica; e a da teoria ator rede trata o social como algo instável, no qual a sociedade é um processo sempre incompleto e a agência é distribuída entre humanos e não humanos.

A despeito das diferenças entre as três abordagens, concordamos com Bispo (2016) ao afirmar que seus pressupostos são convergentes com a chamada abordagem dos estudos baseados em prática (EBP), fazendo parte de practice turn (virada da prática) nos estudos sobre turismo. Tanto no turismo (Bispo, 2016; Lamers, Duim \& Spaargaren, 2017) como nos estudos organizacionais (Júlio \& Tureta, 2018; Pimentel \& Nogueira, 2018; Sandberg \& Dall’Alba, 2009), essa virada se relaciona com o desenvolvimento de uma diversidade de propostas marcadas por uma epistemologia da prática, na qual o social é situado na prática (Reckwitz, 2002).

Dentro dessa diversidade, assumimos, neste estudo, as propostas de Schatzki $(2001,2002,2003,2005,2006)$ e a concepção que Bispo (2016) chama de turismo como prática. Nessa abordagem, a mobilidade e a performatividade fazem parte de um conjunto de práticas organizadoras - o próprio turismo -, na medida em que ele está continuamente sendo produzido por elas. Isso ocorre porque não existe uma fronteira definitiva entre o turístico e o não turístico; estes dois compõem um todo, sempre dinâmico e inacabado. 0 organizar dessa prática é tratado neste estudo a partir dos entendimentos - habilidades pertencentes às ações em uma prática -, das regras - definições que indicam como proceder - e da teleoafetividade indicação da finalidade, do propósito, combinando emoções, humor e intenções -, que, segundo Schatzki (2002), formam a organização da prática.

É dentro dessa visão dinâmica que consideramos o potencial das práticas para organizar e permitir a compreensão da prática dos roteiros turísticos. Essa visão nos afasta de estudos preocupados em contribuir para a visão do roteiro como algo concreto, planejado por uma organização que define uma sequência de locais físicos a ser visitados (Li et al., 2016).

A abordagem aqui adotada permitiu acessar e contribuir sobre outros aspectos do roteiro ao utilizar a epistemologia de Schatzki, que colabora para investigar o seu organizing, ou seja, o seu contínuo processo de construção e reconstrução no organizar da e na prática (Czarniawska, 2008; Schatzki, 2006). Nos estudos organizacionais, essa epistemologia já revelou esse potencial, favorecendo a compreensão de situações imprevistas de atividades humanas e do arranjo material relacionado, por exemplo, com a busca pelo luxo e os limites da escassez de recursos nos desfiles de escolas de samba (Júlio \& Tureta, 2018). Na discussão sobre o roteiro turístico, essa epistemologia oferece um caminho para pesquisadores desenvolverem novos estudos que explorem esse potencial e para membros organizacionais, relacionados com a formulação e a execução de roteiros, refletirem sobre suas ações nas imprevisibilidades na prática do roteiro.

Essas contribuições se viabilizam pelo que justificativa a adoção da epistemologia da prática de Schatzki (2001, 2002, 2003, 2005, 2006): o potencial de compreensão obtido ao tratar a prática do roteiro turístico dentro do entendimento de prática, como atividades humanas organizadas, sustentadas em arranjos materiais, e permeadas por imprevistos. Neste estudo, essa epistemologia nos permite propor que o roteiro turístico é uma prática, sempre em (re)construção, organizada nas regras, nas habilidades e na teleoafetividade que compõem a prática e remetem à produção de um conjunto de vivências turísticas consideradas pelos praticantes como interligadas entre si no tempo. Com base nessa proposição, para ampliar nossa compreensão sobre os roteiros turísticos, devemos acessar a sua prática, conforme realizado neste estudo ao investigar o seguinte problema de pesquisa: como o organizar da prática de roteiros turísticos é revelado a partir da epistemologia da prática de Schatzki?

Com base nessa questão, o objetivo deste estudo foi compreender o organizar da prática de roteiros turísticos a partir da epistemologia da prática de Schatzki. A proposta desenvolvida permitiu tratar de elementos do organizar pouco estudados no campo do turismo e dos estudos organizacionais, contribuindo para ambos. Eles se manifestaram na produção do roteiro pela via da prática, envolvendo turistas, membros organizacionais voltados para atender demandas do mercado turístico, entre outros atores, em interações com elementos materiais. As demandas se revelaram voltadas para a surpresa, para o inesperado, para a ruptura de padrões organizacionais, como parte da sua (re)produção, evidenciando aspectos do organizar que não são exclusivos do campo do turismo, fazendo parte, também, do campo dos estudos organizacionais. 
As referidas contribuições foram evidenciadas empiricamente por meio de uma pesquisa qualitativa. A coleta de dados foi realizada por meio de pesquisa documental, entrevistas informais e observações participantes. 0 tratamento dos dados ocorreu a partir de temas definidos a posteriori por meio do procedimento da análise em espiral.

Para desenvolver a discussão, tratamos do campo de estudo dos roteiros turísticos, para, depois, apresentar os EBP no campo do turismo e a epistemologia da prática de Schatzki. Em seguida, apresentamos o percurso metodológico e os dados sobre a agência de turismo e a prática do roteiro investigada. Por fim, analisamos os resultados com base na articulação teórica, e apresentamos as considerações finais do artigo.

\section{O CAMPO DE ESTUDO DOS ROTEIROS TURÍSTICOS}

Dentro da diversidade de abordagens no campo dos estudos sobre roteiros turísticos identifica-se duas grandes perspectivas: a primeira que concebe os roteiros turísticos como mapas prescritos (Fageda, Jiménez, Perdiguero \& Marrero, 2017; Li et al., 2016; Stone, 2016; Sudiarta \& Suardana, 2016). E a segunda para a qual os roteiros turísticos são rotas experienciais de acordo com os trabalhos de Cisne e Gastal (2011), Cutler, Carmichael e Doherty (2014), Jiang e Xu (2016).

Na primeira perspectiva, de diferentes maneiras, os autores se voltam para o caráter prescritivo do roteiro e para as relações de causalidade com as variáveis que o definem. Nessa ótica, Li et al. (2016) apresentam uma ferramenta com o propósito de minimizar os custos dos itinerários para os turistas, tratando o roteiro como um conjunto de locais físicos de passagem. De maneira semelhante, Fageda et al. (2017) tratam a rota como uma passagem entre lugares visitados, posicionando o estudo do roteiro como um meio para analisar influências dos tipos de companhias aéreas, destacando as operações caracterizadas como de baixo custo. Essa relação de causalidade com determinadas variáveis também fica evidente no estudo de Stone (2016), com foco nas implicações dos atrasos e cancelamentos em pequenos aeroportos; e no de Peng, Zhang, Liu e Yang (2016), voltado para o fluxo de turistas. Em um exemplo mais prescritivo, Moraes e Emmendoerfer (2015) propõem a definição de estratégias em núcleos de turismo em comunidades a partir de diagnósticos semelhantes às pesquisas de satisfação do consumidor, tendo o roteiro como parte do consumo.

Esses estudos, comumente, priorizam diagnósticos quantitativos, que servem tanto para questões pontuais, como hierarquizar atrativos turísticos (Dantas \& Melo, 2011), quanto para planejamentos mais amplos de destinos turísticos (Sudiarta \& Suardana, 2016). Nessa perspectiva, a montagem de um roteiro se relaciona com a capacidade de predição dos padrões de movimentação e do tempo investido pelos turistas (Xia, Zeephongsekul \& Arrowsmith, 2009). Tais estudos contribuem para a objetivação dos roteiros turísticos, a partir da compreensão de determinadas variáveis que os envolvem.

A despeito dessa contribuição, há certa limitação na falta de potencial para a compreensão da dinâmica mais complexa dos roteiros turísticos, como algo mais do que itinerários de viagem (Cisne \& Gastal, 2011). Os estudos inseridos na segunda grande abordagem sobre os roteiros, que os trata como rotas experienciais, estão mais voltados para esse potencial e se afastam da referida objetivação. Nessa ótica, Cisne e Gastal (2011) se baseiam na teoria da complexidade para discutir o turismo em termos de sua dimensão epistemológica, buscando uma contribuição social reflexiva sobre a atividade.

Estabelecendo outra crítica à abordagem prescritiva, Cutler et al. (2014) discordam do foco dado no destino e não na viagem. Para os autores, é necessário reconhecer o significado relacionado à autoidentidade da pessoa na experiência turística e na percepção na e sobre a viagem, em uma ênfase epistemológica do turismo que reconhece as produções de conhecimento a ele relacionadas.

Com certa aproximação com essa última abordagem, Jiang e Xu (2016) se inserem na chamada perspectiva geográfica literária, que alia o estudo da experiência antes e depois do roteiro com as relações com a leitura de textos ligados à experiência turística. Aqui temos esta analogia: assim como o leitor lê o texto escrito por um autor e o interpreta de diferentes maneiras, o turista, em suas interações sociais, interpreta de diferentes maneiras o roteiro previamente planejado.

Esse último estudo e os demais, aqui inseridos na abordagem do roteiro como experiência, ressaltam as interações cotidianas e o caráter epistemológico do turismo. Tais aspectos indicam uma maior aproximação deste estudo com essa última abordagem. Entretanto, não foram identificados estudos sobre a prática do roteiro em seu caráter ontológico, em interações sociais e materiais que produzem o organizar da prática do roteiro e são produzidas por ela. Propomos trazer essas contribuições para o campo de estudo dos roteiros turísticos a partir de articulações com os EBP e o foco no organizar. 


\section{OS EBP NO CAMPO DO TURISMO E A EPISTEMOLOGIA DE SCHATZKI NO ESTUDO DOS ROTEIROS TURÍSTICOS}

Ao longo dos anos, contribuições específicas das teorias da prática (Reckwitz, 2002) têm sido abarcadas pelo campo do turismo. Entre elas, a materialidade se destaca na prática do turismo (Rantala, Valtonen \& Markuksela, 2011). Edensor (2001), por exemplo, a articula diretamente com outros elementos da prática, quando considerou o turismo um conjunto de atividades imbricadas em um cotidiano de improvisações.

O autor trata o turismo em termos de negociações performativas influenciadas pelo poder social e cultural. Essa performatividade ocorre de forma reflexiva, em um processo de conhecer, o chamado knowing. O verbo substitui o uso do substantivo knowledge e afasta a ideia de um conhecimento definido e estático para reconhecer seu processo contínuo de (re)constituição presente nas práticas (Nicolini, Gherardi \& Yanow, 2003). Sob essa ótica, diversos estudos tratam o organizar da prática do turismo como espaços de construção de sentidos, significados e knowing (Bispo, 2012, 2016; Bispo \& Godoy, 2012; Roper \& Hodari, 2015). Nesse entendimento, com base em influências de Schatzki $(2001,2006)$, entre outros autores, Bispo (2016, p. 174) apresenta o turismo como prática como uma noção na qual o turismo é "um conjunto de práticas organizacionais contínuas", a ser compreendido a partir do knowing, dos fazeres e dos dizeres, por meio dos quais sabemos realizar as ações que desejamos no turismo, ou seja, no seu espaço de contínua construção.

Neste artigo, defendemos que o organizar do roteiro turístico também é um elemento importante dessa contínua construção. Para isso, dentro da diversidade de abordagens nos EBP, também assumimos influências da epistemologia da prática de Schatzki $(2001,2002,2003,2005)$. O autor oferece contribuições aplicáveis nos estudos sobre roteiros turísticos ao tratar do chamado organizing. $\mathrm{O}$ termo indica o caráter dinâmico e sempre incompleto do processo de organizar, um entendimento ilustrado pela substituição do substantivo organization pelo verbo organizing. Para investigar as organizações a partir da ideia de organizing, é necessário considerá-las da maneira como ocorrem - em uma ótica dinâmica (Schatzki, 2006). O autor se aprofunda em duas questões básicas no tocante ao organizing, que contribuem para a compreensão do organizar da prática do roteiro: a performance das ações, e as práticas que a constituem; e a ocorrência de eventos em arranjos materiais que sustentem essas atividades.

A partir dessa visão, o roteiro turístico é considerado aqui uma (re)organização, em tempo real, em torno de práticas e arranjos materiais que incluem formas que perduram e têm o planejamento prévio do roteiro como apenas uma parte de outras interações, na prática do roteiro turístico. Ao propormos esse conceito, contribuímos para o reconhecimento de que, nessa prática, há a produção de um roteiro turístico quando vivências turísticas são associadas entre si e a determinado tempo e espaço pelos praticantes. Esse processo não cessa quando uma pessoa chega em sua residência. As interações que o reconstroem podem ou não continuar em ação, como no caso de arranjos materiais marcados por um souvenir - uma réplica de um monumento exibida na sala ou esquecida e jogada no lixo, ou uma faixa feita de papel higiênico pelos turistas para premiar a turista mais animada durante um trajeto de ônibus. A premiação com a faixa de papel pode ser esquecida no mesmo dia, ou ser lembrada ao longo de toda uma vida por quem a deu e/ou a recebeu.

Esses arranjos materiais estão imersos nas redes de prática. Segundo a epistemologia aqui adotada, são compostas pelas ações de várias entidades, não apenas as de pessoas (Schatzki, 2002). Portanto, entendemos a prática como atividades humanas organizadas, "um nexo organizado de ações" ou, ainda, um "pacote" de ações composto pelos fazeres (doings) e dizeres (sayings) e por arranjos materiais (Schatzki, 2002, p. 71). Para o autor, o não fazer e o não dizer fazem parte dessas práticas, assim como o dizer sem a fala, pois ocorre nos gestos. Além disso, uma mesma ação pode fazer parte de mais de uma prática, o que faz com que não exista uma linha divisória entre elas. Nessa multiplicidade de práticas, ocorre uma recursividade que as altera, já que suas atividades também não são sempre iguais. Contudo, possuem semelhanças, construindo uma ordem social composta por um arranjo de pessoas, artefatos e coisas em torno dos quais as ações e seus significados são situados no tempo e no espaço (Schatzki, 2001).

Nessa ordem social, as práticas são governadas por uma inteligibilidade prática, que é o que faz sentido para uma pessoa ao realizar determinada atividade (Schatzki, 2002). Faz-se necessário, para compreender a intencionalidade nessa realização, entender três elementos em torno dos quais as práticas se organizam, os quais se ligam aos fazeres e dizeres de uma prática e formam sua organização (Schatzki, 2002, 2005): entendimentos; regras; e teleoafetividade. 
Os entendimentos se referem ao knowing-how, ou seja, a certas habilidades pertencentes às ações que compõem uma prática, e, assim como a prática, se repetem ao mesmo tempo que mudam e são compartilhados pelos indivíduos imersos em uma prática (Schatzki, 2002). As regras surgem na socialização dos indivíduos, quando aprendem quais regras organizam as práticas em que estão imersos - por exemplo, normas e instruções sobre como proceder, convenções e prescrições sociais -, além de princípios socialmente compartilhados (Schatzki, 2002). Para Santos e Silveira (2015), as regras podem representar uma codificação das ações passadas que direcionam uma orientação de como as ações futuras devem ser executadas. A teleoafetividade indica uma finalidade, um senso de propósito caracterizado por uma complexa combinação de emoções, humor e intenções. A estrutura teleoafetiva que organiza uma prática é socialmente compartilhada e composta por uma série de projetos, tarefas e objetivos normatizados e hierarquicamente ordenados (Schatzki, 2002).

Santos e Silveira (2015) evidenciam que as regras organizam as práticas e as atividades realizadas pelos indivíduos, ao passo que o entendimento e a teleoafetividade organizam o que faz sentido para os praticantes fazerem. $O$ entendimento geral de uma prática é social, existindo uma estrutura compartilhada por esses três elementos, chamada por Schatzki (2005) de estados mentais, que é dinâmica e organiza as práticas.

Nessa concepção de organização das práticas, Schatzki $(2001,2005)$ aborda a ontologia de contexto (site ontology), segundo a qual a vida social está relacionada a um contexto de que ela é mais uma parte. $\mathrm{O}$ autor posiciona o contexto como uma arena social, na qual ocorrem práticas e fenômenos sociais, ao mesmo tempo que essa própria arena é constituída por entidades sociais, materiais e toda a malha e o arranjo de práticas. Esse contexto social pode ser, por exemplo, um roteiro turístico composto pelas atividades humanas, pelos materiais, além da malha e do arranjo de práticas que constituem a prática de um roteiro. Defendemos que a compreensão de como ocorre essa composição oferece elementos relevantes, aqui explicitados, capazes de ampliar o entendimento da dinâmica dos roteiros turísticos. Essa proposição foi legitimada empiricamente, ao ser aplicada em uma investigação produzida a partir dos aspectos metodológicos apresentados a seguir.

\section{ASPECTOS METODOLÓGICOS}

O método adotado foi o qualitativo, tendo como principal instrumento de coleta de dados a observação, escolha considerada adequada para identificar a performatividade na prática (Bispo, 2016). Para compreender situações passadas e aspectos específicos na prática dos roteiros, também foram realizadas entrevistas e pesquisa documental.

A observação foi participante (Cavedon, 1999) e ocorreu entre junho e novembro de 2017, quando um dos autores do artigo participou do cotidiano de uma agência de turismo e de roteiros oferecidos por ela. Foram dois dias de observação na agência, acompanhando atividades internas relacionadas com os roteiros; um dia em um famtour - atividade para operadoras de turismo conhecerem os roteiros; um dia na recepção de um navio de cruzeiro; três dias no roteiro do city tour Vitória/Vila Velha; três dias no roteiro de praia para Guarapari; dois dias no roteiro de praia para Manguinhos; um dia no roteiro de Domingos Martins; um dia no roteiro do agroturismo em Venda Nova do Imigrante.

Durante a observação, foram registradas notas de campo com o aplicativo OneNote no celular, sincronizado com o software Microsoft Word. O uso do celular para o registro se mostrou adequado pois passava despercebido, por ser algo comum a todos. As notas permitiram gerar diários de campo contendo a descrição do que ocorreu a cada dia, os sentimentos, as expressões do grupo, entre outros aspectos (Cavedon, 1999).

Na pesquisa documental (Cellard, 2008), foram coletados registros de incentivos relacionados ao turismo do estado do Espírito Santo, além de documentos internos da agência de turismo referentes aos roteiros e ao atendimento aos turistas.

As entrevistas ocorreram durante as observações e seus dados foram incluídos no diário de campo, pois foram de natureza informal, não estruturada, proporcionando liberdade para o entrevistado e o pesquisador (Fontana \& Frey, 2005). Elas ocorreram em momentos diversos, como durante intervalos de trabalho na agência, deslocamentos no ônibus, refeições e permanência nos atrativos turísticos por estar relacionados a algo específico da prática do roteiro, os seguintes entrevistados foram escolhidos: dois gestores da agência; cinco guias; três motoristas; 47 turistas praticantes dos roteiros; dez atendentes de estabelecimentos; três agentes de turismo; e quatro não turistas presentes na rede de práticas dos roteiros. 
O tratamento dos dados ocorreu a partir de temas definidos a posteriori por meio do procedimento da análise em espiral proposto por Creswell (2012), que consistiu em esboçar ideias, fazer anotações, resumir as notas de campo, trabalhar com palavras, identificar os códigos, reduzir os códigos a temas menores, contar a frequência dos códigos, relacionar os temas, criar um ponto de vista e apresentar os dados. Os códigos mais frequentes serviram para organizar os demais, sendo assumidos como temas básicos. Eles foram caracterizados na forma dos seguintes fazeres e dizeres: quanto tempo tem?; gentileza gera gentileza; tem gosto de quê?; também quero; throwback thursday; conheça o Espírito Santo; miss simpatia; atendimento; outsider; em movimento.

Com o intuito de tornar as articulações teóricas e empíricas mais claras, produzimos um esquema conceitual a fim de demonstrar os caminhos teóricos percorridos para a investigação empírica e suas relações com as categorias definidas a posteriori e, portanto, com os dados empíricos dos quais elas surgiram.

\section{ESQUEMA CONCEITUAL}

Na concepção aqui proposta (Figura 1), partimos da articulação entre a teoria da prática segundo a epistemologia de Schatzki $(2001,2002,2003,2005)$ e o entendimento de turismo como prática de Bispo (2016). Com base nessas contribuições, a investigação das práticas no turismo se volta para seus arranjos materiais, fazeres e dizeres. Tais arranjos compreendem os elementos que organizam as práticas, ou seja, os entendimentos, as regras e a teleoafetividade. A partir do foco aqui proposto, de investigar a prática dos roteiros, tais elementos foram investigados dentro do entendimento de que os fazeres e dizeres permitem uma análise do organizing da prática do roteiro, que compreende entendimentos, regras e teleoafetividade.

Figura 1

Esquema conceitual

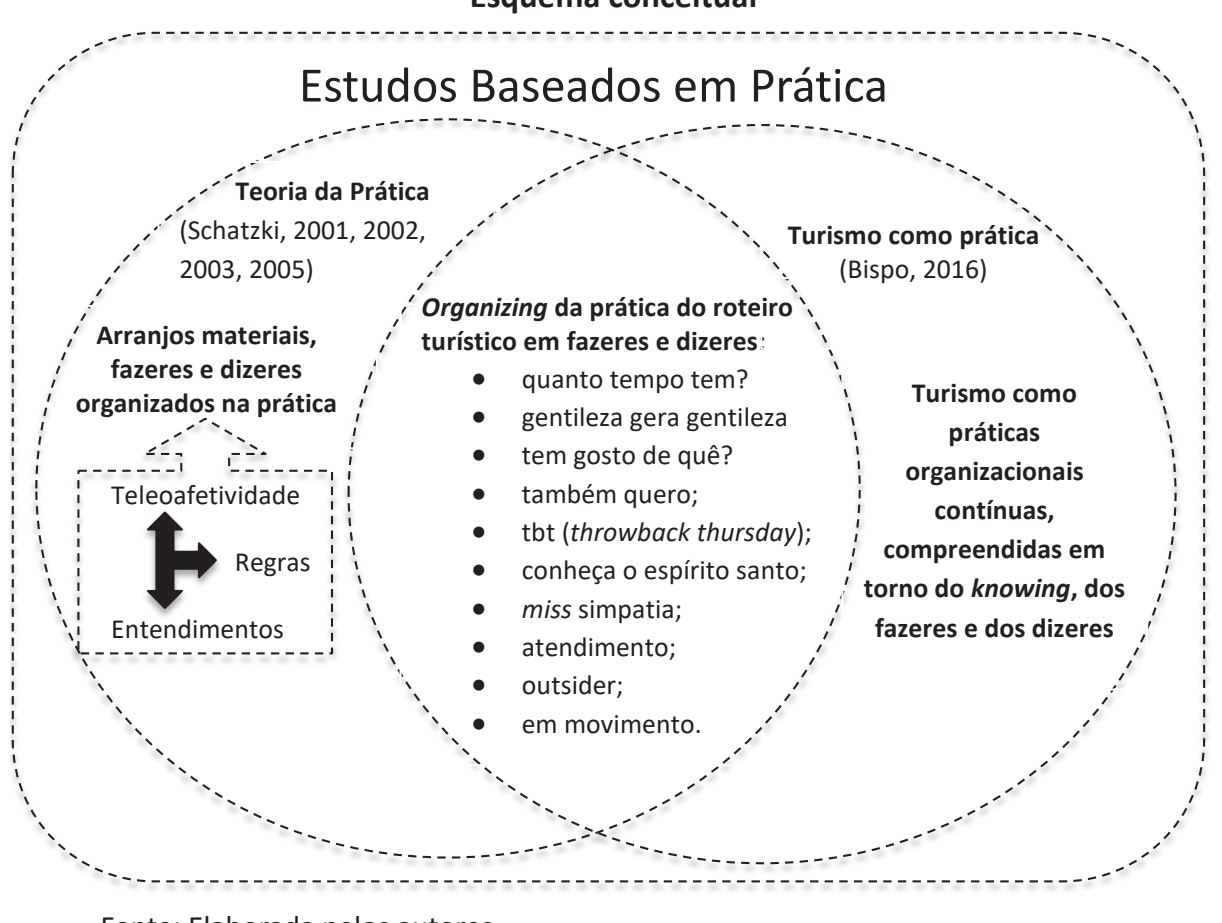

Fonte: Elaborada pelos autores.

Para sustentá-lo empiricamente, esse esquema conceitual foi aplicado à investigação da prática do roteiro em uma agência de turismo. Como resultado, obtivemos os fazeres e dizeres da prática do roteiro turístico apresentados na Figura 1, a partir dos quais foi desenvolvida a análise a seguir. Ela trata desses fazeres e dizeres e dos entendimentos, das regras e da teleoafetividade a eles relacionados. 


\section{A AGÊNCIA E OS ROTEIROS}

A agência de turismo na qual os dados foram coletados está localizada no Espírito Santo e oferece serviços de turismo receptivo no estado, tais como translado, atendimento de aeroporto e passeios para os principais destinos turísticos da região, com destaque para visitas às praias e montanhas em diferentes cidades, além de atividades atípicas (como veremos mais adiante). A seguir, listamos as atividades que foram acompanhadas durante este estudo.

Em relação às praias, Guarapari tem como atrações as praias das Castanheiras, dos Namorados e da Areia Preta. Além da opção extra do passeio de escuna, a agência tem como ponto de apoio um quiosque com cardápio de praia e a visita a uma cachaçaria. O passeio a Manguinhos ocorre em uma praia localizada em uma vila de pescadores, com diversas oportunidades gastronômicas, além da visita ao Galpão das Paneleiras, onde são produzidas panelas de barro tradicionais. O city tour Vitória/Vila Velha, além do tour panorâmico pelas principais praias das cidades e pelo centro de Vitória, contempla a ida ao Convento da Penha, à loja da Fábrica de Chocolates Garoto e à Ilha do Boi.

Como destinos de montanhas, a agência oferecia agroturismo com degustação de produtos regionais, em Venda Nova do Imigrante, e visita aos principais pontos turísticos de Domingos Martins. Esses passeios foram mesclados e agora constam em um único roteiro.

Como atividade atípica temos a recepção de um navio de cruzeiro. Trata-se da recepção dos turistas que desembarcam, com indicações sobre a localização de táxis e a saída do porto.

\section{A PRÁTICA DOS ROTEIROS}

A descrição da prática dos roteiros está organizada a partir do conjunto de categorias desenvolvidas a posteriori, que são os fazeres e dizeres identificados. A seguir, elas foram apresentadas separadamente ou em pares, mas na prática não há uma sequência fixa ou uma separação - várias surgem simultaneamente. A separação ocorre apenas para fins de organização do texto, com o intuito de que a argumentação fique mais clara.

\section{“QUANTO TEMPO TEM?”}

Na prática dos roteiros, vários temas indicaram a tensão entre o roteiro formal e a sua prática. Um deles foi o tempo, relacionado aos períodos de deslocamento, interação com elementos do roteiro e funcionamento das atrações.

Por exemplo, durante um dos roteiros, as lojinhas fechadas em uma rua passaram a ser o cenário de um tempo de deslocamento e não de parada, como previsto. $O$ espaço turístico, previamente planejado, passou a ser uma rua de passagem em função do movimento no tempo. Outro exemplo foi quando chegamos muito cedo ao Galpão das Paneleiras de Goiabeiras. As paneleiras ainda chegavam e não pareciam dispostas a trabalhar tão cedo. Os turistas entraram no galpão, ouviram a guia sobre a produção artesanal das panelas, olharam rapidamente o trabalho de uma única senhora e se juntaram do lado de fora. A relação com o tempo levou a um desinteresse mútuo, prejudicando a planejada interação com as paneleiras, que deveria ocupar um tempo muito maior.

Por outro lado, também era comum a preocupação com uma possível falta de tempo, surgindo a pergunta: “Quanto tempo tem?". O tempo exigia pressa de quem ficava para trás, enquanto outros aguardavam para ver a próxima atração.

Outro tema, a gentileza, se relacionava socialmente com o tempo. A gentileza de quem esperou os atrasados é sustentada na certeza da reciprocidade no tempo futuro, pois, na prática dos roteiros observados, "gentileza gera gentileza". 


\section{“GENTILEZA GERA GENTILEZA”}

Diversas regras de gentileza, estabelecidas de forma tácita, eram compartilhadas pelos praticantes do roteiro. Essas regras organizavam atividades da prática (Schatzki, 2002). Por exemplo, não existia uma placa no micro-ônibus com a frase "ao entrar, diga bom-dia", mas as pessoas entravam cumprimentando quem estava lá dentro. Ou quando os turistas tiravam fotos: quando um grupo estava fotografando, os demais aguardavam e até ajudavam nas fotografias.

Contudo, a falta de gentileza gerava falta de gentileza, como a exclusão por parte do grupo. Um episódio deixou muito clara essa relação:

[Uma] das senhoras usava uma muleta, mas quando ela entrou no ônibus os lugares da frente já estavam reservados e uma [terceira] senhora comentou: 'Já pegaram o seu lugar?' [...]. Uma das turistas deu a ideia de isolar a senhora que guardou os lugares, então elas contaram os lugares e todos começaram a ocupar o ônibus de trás para a frente. As pessoas que já estavam dentro do ônibus mudaram suas coisas para trás e todos que chegavam eram avisados sobre o 'motim'! [...]. Após todos os turistas estarem no ônibus, o guia e eu também entramos, e a senhora que havia guardado os lugares e uma amiga que estava com ela ficaram isoladas e separadas por duas fileiras de poltronas vazias. Durante alguns instantes elas se apoiaram no encosto da cadeira para olhar para atrás e tentar entender o que estava acontecendo. Percebi que momentos depois elas compreenderam que a separação em relação às outras pessoas foi proposital e que o fato de as cadeiras estarem reservadas não agradou o restante do grupo (Diário de campo).

Aqui temos duas regras em questão: não guardar lugar; e reservar lugares na frente para idosos e pessoas com deficiência (uma regra formal e explícita na sinalização do ônibus). Como quase todos eram idosos, eles poderiam se sentar em qualquer assento, mas o grupo compartilhava de ideia de que quem chegava poderia se sentar no assento de sua preferência, sem "reserva" para quem não estivesse presente, e que pessoas com deficiência teriam prioridade. Ao não obedecerem a essas regras, as duas mulheres produzem, em conjunto com os demais praticantes, efeitos inesperados na prática do roteiro, tornando-o único, a despeito de ser um roteiro que já ocorreu centenas de vezes. A prática do roteiro ia além do guia e de diretrizes da agência - ela incluía a interação de humanos turísticos e elementos materiais turísticos, como fotos, ônibus e assentos.

Ainda no tocante às regras, uma se destacou das demais: a experimentação de tudo que fosse possível, seguida da pergunta "tem gosto de quê?".

\section{“TEM GOSTO DE QUÊ?”; “TAMBÉM QUERO”}

Na experimentação durante o roteiro, um praticante do roteiro tomava a iniciativa de experimentar algo, e em seguida vários perguntavam: "tem gosto de quê?". Então, todos experimentavam. Isso foi registrado diversas vezes:

[...] a mulher estava com uma frutinha nas mãos. Logo, ela me parou e perguntou 'Pode comer? Tem gosto de quê?'. Respondi que podia comer sim [...] e que tinha um gosto que eu não sabia explicar direito [...], finalmente, a mulher experimentou a frutinha e disse que não estava muito doce, mas comeu até o fim! [...] Após a explicação do guia sobre o café do jacu [a ave come o fruto do café e expele o caroço alterado pela digestão] [...] uma das moças que estavam conversando comigo se animou para experimentar e disse: 'Apesar de eu não gostar muito de café quero experimentar esse diferente'. Logo ela bebeu um gole do café sem açúcar e não fez cara boa, o pai bebeu outro; ela adoçou o café e bebeu o restante - um outro casal e eu também pedimos uma xícara (Diário de campo).

A regra da experimentação leva à aceitação do elemento material turístico desconhecido. Isso é esperado pelos praticantes, pois eles compartilham essa regra organizadora das atividades na prática do roteiro. Inclusive há o embate entre a experimentação e as preferências pessoais construídas ao longo de uma vida. Isso ocorreu quando quem não gostava muito de café o tomou, e, em outros momentos, quando "pessoas que não gostavam de licor degustaram todos os sabores disponíveis, as que não comem cebola experimentaram a 'cebola bêbada' [...]" (Diário de campo). 
Nessa dinâmica, os turistas, ao observarem os outros fazendo ou comprando algo, manifestavam o "também quero". Isso remete à finalidade de agir como e com os demais ao conhecer o que os outros conheceram; fotografar o que os outros fotografaram, inclusive com as mesmas poses; parar nas mesmas lojas; comprar o que os outros compraram etc.

O entendimento do "também quero" revela como o material comercializado, ao ser transformado em turístico, vai além do comércio de um produto. Ele é, também, uma produção que faz parte da prática do roteiro em suas relações com e entre os próprios turistas, nas quais um turista é habilitado para ser atração para o outro. Entre todos os "também quero", as fotos assumiram um contorno tão característico que se destacaram como uma categoria específica de fazer e dizer, dentro do que foi chamado de throwback thursday.

\section{THROWBACK THURSDAY, “CONHEÇA O ESPÍRITO SANTO”}

O termo throwback thursday faz referência a uma hashtag homônima utilizada nas redes sociais durante as quintas-feiras para postar fotos que remetam a inúmeras lembranças. A construção de lembranças em fotos foi o tema mais observado, ficando evidente em vários exemplos de elementos da prática do roteiro discutidos até aqui. Existe um compartilhamento social em torno de sentimentos e do objetivo de produzir lembranças e outros sentimentos ao visualizar e enviar fotos para amigos e familiares, durante a prática do roteiro, algo marcante na estrutura teleoafetiva que a organiza.

O praticante retratava a si mesmo, os amigos e os familiares em conjunto com belezas do estado do Espírito Santo, onde ocorreram os roteiros, como quem diz "conheça o Espírito Santo". Em seus comentários, ao tirar e enviar fotos, ficava evidente que os sentimentos sobre as belezas naturais do estado marcavam a estrutura teleoafetiva da prática dos roteiros, com praticantes indicando o compartilhamento do objetivo de buscar a proximidade com a natureza e com as pessoas.

Essa finalidade de proximidade com as pessoas já foi esboçada quando revelamos que um turista serve de atração para o outro. No limite, eles procuram um ideal que chamamos aqui de a busca pela "miss simpatia".

\section{"MISS SIMPATIA"}

A miss simpatia pode se materializar em uma pessoa, mas é mais do que isso - é o indicativo de uma finalidade em torno da qual o roteiro se organiza. A simpatia envolve a interação entre os agentes da prática, os humores e afetos entre eles. Nas observações, essas manifestações foram recorrentes. Por exemplo:

[...] em Vitória a guia disse que no dia seguinte faria outro passeio, portanto não faria o transfer out delas. A coordenadora do grupo agradeceu a guia e passou a palavra para outra senhora, que também agradeceu o carinho e a paciência em nome do grupo e disse que, para homenagear a guia, elas cantariam uma seresta da terceira idade. A guia agradeceu e chorou, até eu chorei. A guia disse 'cada grupo é um grupo e eu fico muito feliz por ter conhecido vocês'. [...] todas as senhoras abraçaram a guia, tiraram fotos com ela e, por fim, ela foi presenteada com uma camisa do grupo. [...] uma senhora estava fazendo selfies e me pediu para fotografá-la. Tirei fotos de um ângulo, de outro, ajeitei a canga dela, fiz umas fotos panorâmicas [...]. Por fim, ela disse que estava adorando porque a cidade é muito bonita, muito limpa e as pessoas muito simpáticas (Diário de campo).

O trecho acima evidencia a teleoafetividade organizando a prática no sentido da interação entre praticantes, vendo nos outros uma "miss simpatia" em potencial.

Fica evidente o caráter transformador da prática do roteiro sobre humanos e materiais. Por exemplo, quando um humano se transforma em "miss simpatia", ou quando um café, mesmo não sendo apreciado por alguns humanos, é bebido por eles no roteiro. O humano e o material alteram a sua relação durante o roteiro, o turista se transforma em humano turístico e o café em material turístico, ou seja, o café turístico.

Essa transformação envolve diversas atividades dentro da prática, com destaque para o atendimento. 


\section{O “ATENDIMENTO”}

Ao longo da prática do roteiro, os elementos materiais já mencionados, como o café do Jacu e a "cebola bêbada", transformam-se em material turístico também pela maneira do atendimento, quando são oferecidos na prática do roteiro, nas ações do guia e demais agentes. $O$ café e a cebola, por exemplo, deixam de ser comuns, a partir do atendimento, quando são apresentados, respectivamente, como "do Jacu" e "bêbada", transformando-se em café e cebola "turísticos".

As regras já mencionadas organizam essa transformação dentro da atividade de atendimento, assim como essa atividade ganha sentido por uma teleoafetividade com implicações específicas. Ela dá sentido à dinâmica da prática para o praticante (Schatzki, 2002). Sentimentos relacionados à felicidade e à simpatia, entre outros, envolviam o propósito da busca pela satisfação na prática do roteiro, dando sentido a ela e a um tipo de atendimento ligado à satisfação, quando os praticantes percebem a necessidade dos agentes em agradá-los.

Por exemplo, quando a pesquisadora acompanhava um grupo de turistas, os mesmos garçons, que apenas atenderam os grupos em roteiros anteriores, dessa vez os levaram para conhecer a igrejinha da região. Os garçons foram sempre muitos simpáticos e pareciam à vontade. A prática daquele dia foi diferente; a visita à igreja não faz parte da definição formal do roteiro. A relação criada entre os praticantes e os garçons, na prática do roteiro, levou à inserção de outro elemento material turístico. Ficaram evidentes os sentimentos positivos envolvendo a satisfação, a simpatia e a busca por agradar, marcando a teleoafetividade na reorganização da prática do roteiro.

O elemento material se transforma em um material turístico oferecido aos turistas. A igreja se transforma por uma relação que vai além da materialidade de um templo religioso. Ela ocorre, também, em função das relações entre guia, turistas e demais agentes na prática. Há um entendimento comum no qual eles estão habilitados para isso em torno de uma prática (Schatzki, 2002).

Mas nem todo praticante do roteiro compartilhava de maneira absoluta os entendimentos na prática, posicionando-se como um outsider.

\section{O OUTSIDER “EM MOVIMENTO”}

Em relação a alguns poucos praticantes, e em alguns momentos específicos, não havia consenso no sentido do que fazia sentido ou não fazer ou dizer. Eles foram aqui identificados como outsider. Um exemplo ocorreu na visita às paneleiras de Goiabeiras.

[...] o casal falou comigo 'nossa, esse jeito de queimar não deveria ser assim, libera muita fumaça, é feito ao ar livre. Olha como as pessoas ficam no sol, elas têm a pele castigada e respiram toda essa fumaça'. Eu justifiquei e lembrei a eles que a guia havia dito que é uma tradição passada de mãe para filha e eles nem me deixaram completar a frase, retrucando 'eu sei, mas eles deveriam evoluir. Se for para melhorar, tudo tem que mudar' (Diário de campo).

O não compartilhamento de alguns entendimentos entre turistas ocorria algumas vezes na prática do roteiro. Para lidar com esse fenômeno, evidenciamos no organizar da prática um entendimento que habilita o uso do tempo envolvendo contínuas mudanças, um "em movimento" mantido pelos guias. Nele os não compartilhamentos vão surgindo e sendo deixados para trás, na medida em que o praticante move, continuamente, o foco de suas interações (como o casal, indignado com o processo produtivo das paneleiras, que, em outro espaço-tempo do roteiro, não tratava mais disso).

Por sua vez, esse "em movimento" se relacionava, frequentemente, com outros fazeres e dizeres, tais como: quanto tempo tem?; tem gosto de quê?; também quero. Ou seja, os fazeres e dizeres não se apresentavam de maneira isolada na prática do roteiro, muito pelo contrário. Na prática, os fazeres e dizeres organizados em torno de regras, teleoafetividades e entendimentos aqui discutidos são interligados. Eles foram apresentados separadamente a partir das categorias de análise apenas para fins de organização do texto. As regras, os entendimentos e a teleoafetividade apresentados separadamente estão imersos em uma mesma rede de práticas e influenciam e são influenciados uns pelos outros no organizar da prática do roteiro. 


\section{ANÁLISE DOS RESULTADOS: A EPISTEMOLOGIA DE SCHATZKI NA PRÁTICA DO ROTEIRO}

Nos dados, ficou evidente que os arranjos materiais são um aspecto relevante da abordagem das práticas do turismo, já identificados no estudo de Rantala et al. (2011). No presente estudo, tais arranjos se mostraram produtores da prática do roteiro, a exemplo das relações entre os praticantes e o café, as fotos, as cadeiras do ônibus, entre outros.

Outro aspecto da materialidade no roteiro é o seu caráter histórico e informativo sobre uma localidade. Os guias evidenciaram na prática do roteiro o domínio dessas informações adquiridas durante o curso de guia turístico. Mas as habilidades dos guias não se restringiam a esse curso - apenas faziam parte de um knowing (Gherardi, 2009) que continua se estabelecendo a partir da prática do roteiro.

Ou seja, assim como observado nos estudos de Bispo (2012), Bispo e Godoy (2012) e Roper e Hodari (2015) sobre a prática do turismo, na prática do roteiro também identificamos os processos de conhecer em uma prática e a aprendizagem nessa prática construindo um conhecer. O compartilhamento desse conhecer remete à corporificação dos sujeitos em uma prática, como evidenciado na discussão do tema "em movimento", quando os humanos turísticos revelaram a necessidade de explorar todos os lugares pertencentes à prática do roteiro.

Os indivíduos também compreenderam, a partir daquele knowing, que a prática do roteiro necessitava de movimento e exploração dos locais para a compreensão do contexto, e ficaram atentos aos possíveis locais de visitação e às experiências que poderiam vivenciar. Esse knowing marca como ocorre o movimento dos corpos dos indivíduos que, por meio da aprendizagem, é produzido pela prática (Reckwitz, 2002; Schatzki, 2001, 2002) do roteiro. Consequentemente, o andar foi estabelecido como um dos movimentos do corpo guiado pela prática, assim como o ouvir e o falar foram algumas formas de performatividade na prática do roteiro.

Apesar da corporificação e performatividade serem veiculadas pelos sujeitos, a abordagem adotada tornou evidente que todos (corporificação, performatividade, sujeitos) pertencem à prática do roteiro. Em uma conexão com o organizar descrito por Schatzki (2006), a abordagem aqui articulada se volta para a importância do reconhecimento da interação dos elementos humanos e materiais, turísticos e não turísticos, capazes de alterar a prática do roteiro, que se (re)organiza constantemente.

Dessa maneira, a performance das ações e práticas dos sujeitos se altera (Schatzki, 2006), mesmo com os arranjos materiais que sustentam um roteiro sendo compostos por vários dos mesmos objetos (ônibus, placas, restaurantes) e locais de visitação. Isso ocorre porque há uma infinidade de variações possíveis, com destaque para os elementos humanos, que no roteiro são diariamente diferentes. Esses elementos humanos carregam diferentes práticas que os tornam únicos ao interagir com outros humanos e com os arranjos materiais na (re)organização da prática do roteiro turístico.

Como explica Schatzki (2002), essa dinâmica surge porque as ações na prática são situadas no tempo e no espaço, e em tempos e espaços distintos as ações de uma prática não possuem necessariamente o mesmo significado (como no caso em que a senhora guardou lugar num dos assentos da parte da frente do ônibus, mesmo sabendo que uma integrante do grupo tinha um tipo de deficiência física, mas não queria perder o lugar ela). Essa ação pode ter como significados a busca pela melhor visão que o ônibus pode proporcionar à praticante que quer usufruir do trajeto; uma simples distribuição dos lugares; ou o egocentrismo que ignora as necessidades alheias e deve ser punido.

Os diferentes significados fazem parte da dinâmica de alterações das práticas. Em alguns casos, interações anteriores e externas ao roteiro já marcavam alterações em sua prática - por exemplo, quando problemas familiares dos guias ou motoristas interferiam na dinâmica do roteiro. Além disso, embora o mapa prescrito para a realização do roteiro fosse o mesmo, as interações existentes na prática o alteravam, mesmo existindo semelhanças. Isso ocorre devido à existência de uma inteligibilidade prática (Schatzki, 2002), manifestada na prática do roteiro - a partir da necessidade de estar em constante movimento, de tirar muitas fotos, de experimentar todos os sabores e de o guia apresentar informações sobre a materialidade do roteiro, por exemplo.

Isso ficou claro ao analisarmos, a partir da epistemologia de Schatzki $(2002,2005)$, os fazeres e dizeres, expondo entendimentos, regras e teleoafetividade que organizam a prática do roteiro. Embora tais elementos tenham surgido separadamente nas categorias descritas na apresentação da prática do roteiro, eles podem compreender as mesmas ações e orientar as atividades em torno de uma mesma prática. De maneira semelhante ao que foi evidenciado por Schatzki (2002), identificamos regras 
organizadoras da prática compartilhadas durante a socialização dos indivíduos. Assim como revelado pelo autor em relação a outras práticas, embora as normas e instruções que orientam a prática do roteiro sejam as mesmas, as convenções sociais e os princípios compartilhados podem ser diferentes porque envolvem a inteligibilidade da prática. Isso parece ter relação com o fato de esses indivíduos serem de regiões diferentes. Dessa maneira, à medida que os sujeitos se relacionam e interagem, o compartilhamento das regras começa a ser mais homogêneo. $\mathrm{O}$ mesmo ocorre com os entendimentos compartilhados pelos indivíduos imersos em uma mesma prática.

Tanto os entendimentos como as regras que orientam a prática do roteiro estão relacionados com a teleoafetividade evidenciada em momentos como as interações geradas a partir da simpatia, dos sentimentos e das emoções ao conhecerem parte do estado do Espírito Santo, e da necessidade de registrar tais sentimentos por meio de fotos.

A interação de todos esses elementos interfere, de maneiras diferentes, na prática do roteiro e são úteis para o seu estudo. Neste artigo, buscamos revelar esse caminho como uma contribuição para compreender a dinâmica da organização de um roteiro turístico, o que permite discutir suas implicações para os praticantes interessados em atuar nesse organizar.

\section{CONSIDERAÇÕES FINAIS}

O objetivo deste artigo foi compreender o organizar da prática de roteiros turísticos a partir da epistemologia da prática de Schatzki. Assim, foi possível evidenciar o potencial dos EBP para investigar o organizing da prática dos roteiros turísticos em torno de entendimentos, regras e teleoafetividade.

A análise demonstrou a capacidade da prática do roteiro de transformar os gostos das pessoas. $\mathrm{O}$ caráter transformador da prática dos roteiros turísticos sobre humanos e materiais surge quando esses diferentes elementos se relacionam nela. Isso é impulsionado por existir uma intensa diversidade entre humanos e materiais que nunca se relacionaram antes. Eles entram em contato pela primeira vez durante essa prática e não compartilham plenamente dos mesmos entendimentos e regras. Para lidar com isso, a prática do roteio se revelou composta por compartilhamentos que permitem lidar com o não compartilhamento, com a diferença, ao mesmo tempo que propiciam que a diferença se manifeste. Entre esses compartilhamentos, o mais destacado é o entendimento do constante movimento, em busca de explorar novos sabores, espaços e experiências, habilitando a transformação de humanos e materiais, turísticos e não turísticos.

Nessa movimentação, o roteiro turístico se apresentou, ao mesmo tempo, organizado e organizativo, assim como Cavalcante e Bispo (2018) identificaram no espaço turístico. Os roteiros turísticos analisados organizam espaços turísticos ao mesmo tempo que são organizados por eles, em um movimento no qual espaços não turísticos se transformam em turísticos e vice-versa - como no momento em que o ônibus passava por uma série de lojinhas que deveriam estar abertas para visitação dos turistas, conforme planejado. Porém, como elas estavam fechadas, não havia um espaço turístico naquele momento, apenas uma rua por onde o ônibus passou.

Fica claro que essa relação, em torno do roteiro, entre o espaço turístico e o não turístico, assim como ocorre entre os elementos materiais e os atores, turísticos ou não, não é dicotômica, assim como em qualquer relação entre elementos no turismo como prática (Bispo, 2016). Eles não são separados; ambos fazem parte de um todo e estão sempre lá, sendo performados conforme as práticas em jogo, quando se transformam. Ao revelar esse organizar, este artigo contribui para a compreensão da dinâmica das transformações do que é ou não turístico a partir do roteiro.

Além disso, ao analisar a prática do roteiro turístico, foi possível revelar um tipo de organizar no qual predominam engajamentos temporários em atividades específicas. Isso faz parte da maior complexidade de um organizar voltado para o turismo, quando comparado ao das chamadas empresas tradicionais, pois "[...] o processo de produção e de consumo turístico é essencialmente um sistema complexo de relações entre pessoas e de múltiplas organizações", no qual escolhas relativas ao consumo se manifestam ao longo da própria produção e passam a fazer parte dela (Tomazzoni et al., 2008, p. 138).

Deve ficar claro que a prática do roteiro tem semelhanças com qualquer outra prática organizativa, o que inclui práticas em uma empresa ou fora dela. Na abordagem aqui adotada, nas práticas há uma recorrência na qual a pessoa se torna praticante. Não se trata de uma simples repetição, mas de uma (re)produção que inclui uma produção diferente, o inesperado (Schatzki, 2002). 
No caso deste estudo, aqueles que já praticaram roteiros anteriores (re)produzem vários elementos dessa prática e boa parte deles se refere a maneiras para buscar o inesperado. Isso leva a uma constante (re)organização do que envolve a prática do roteiro quando o inesperado vai ocorrendo com resultados diversos. Por exemplo, o protesto entre turistas pelos lugares no ônibus, as reclamações contra as condições insalubres do modo tradicional de produzir panelas de barro, os turistas aceitando o convite de garçons para visitar uma igreja com eles ou a tentação em experimentar uma fruta estranha.

Uma parte dessa surpresa, desse inesperado, é buscada pelos turistas, faz parte da recorrência cotidiana da prática do roteiro e pode ter sido previamente planejada. Mas outra parte, como o mencionado protesto, simplesmente surge, potencializada por aquela busca, ampliando as constantes (re)organizações na prática. Dessa maneira, evidenciamos a oportunidade de estudar o organizar em uma dinâmica na qual a inserção de elementos novos é intensa para boa parte dos praticantes.

Nos estudos no campo organizacional na ótica do organizing, com base na prática, é necessário reconhecer que algo novo sempre pode ser (re)produzido (Júlio \& Tureta, 2018), e isso não é uma exclusividade do roteiro turístico. Ele oferece, sim, a oportunidade para estudar o organizar que ocorre em função desse novo, em uma intensidade cotidiana. Trata-se de um organizar no qual o novo, o inesperado, ocorre dentro da (re)produção de outros elementos da prática, que, independentemente dessa movimentação, já poderiam incluir o novo, mas, nesse caso, ele é, também, um dos propósitos da prática.

O roteiro turístico ofereceu a oportunidade de estudar esse fenômeno organizacional pouco investigado, mas presente na sociedade, inclusive em outros processos de organizar, como, por exemplo, na prática dos cinéfilos, ao buscarem filmes com cenas surpreendentes ou ainda na prática de jogadores on-line, os quais procuram por desafios inimagináveis. Isso, muitas vezes faz com que filmes e jogos sejam alterados antes, durante e até depois do lançamento, pois eles, os consumidores, interagem com o processo de produção. Uma dinâmica típica de algumas organizações contemporâneas que ofertam um produto com diversas possibilidades de uso e que possibilitam que os clientes escolham a forma como irão consumir os produtos.

Portanto, o roteiro turístico não é apenas uma prática do campo do turismo que teve o seu organizar aqui evidenciado. Ele é, também, a manifestação de um tipo peculiar do organizar, na qual ocorre a busca pela experiência estranha, ao mesmo tempo que ocorre a (re)produção de elementos de uma prática. Neste artigo, o roteiro turístico foi o caminho para revelar parte da dinâmica desse processo nos estudos organizacionais.

Além dessa contribuição para o campo dos estudos organizacionais, este artigo contribui para o campo do turismo ao afastar a discussão sobre os roteiros da ótica tradicional e aproximá-la da pós-moderna. Uma movimentação defendida por Oppliger et al. (2016), pois oferece reflexões mais alinhadas com as demandas da sociedade contemporânea ao repensar os roteiros turísticos. Enquanto na visão tradicional eles são tratados como uma definição prévia, estática, de uma oferta turística, na pós-moderna os roteiros são tratados como parte de produções múltiplas em que turismo, turista e sociedade se produzem mutuamente.

Neste artigo, inserirmos nesta discussão a questão do organizar das práticas a partir da epistemologia de Schatzki, oferecendo um olhar distinto sobre os roteiros turísticos, no qual ele é considerado como uma prática relacionada a processos organizativos, permitindo revelar esses processos. Dessa maneira, assim como o turismo como prática se volta para a produção de conhecimento sobre turismo (Bispo, 2016), a abordagem aqui oferecida se volta para a produção desse conhecimento com foco nos roteiros.

Nós propusemos e evidenciamos empiricamente um caminho para tratar os roteiros turísticos sob determinada ótica que se aproxima das novas abordagens de pesquisa em turismo voltadas para a questão da mobilidade, da performatividade e da teoria ator rede (E. Cohen \& S. A. Cohen, 2012), convergentes com os EBP (Bispo, 2016). Ao adotarmos a epistemologia da prática de Schatzki, nos aproximamos das três para tratar dos roteiros, com a ressalva de que, no lugar da simetria entre agência humana e material da teoria ator rede (Latour, 2005), a abordagem de Schatzki (2002) nos permitiu reconhecer os usos que os humanos fazem dos arranjos materiais, atribuindo relevância a esses últimos, mas não de maneira simétrica aos humanos.

Ao adotar essa abordagem, reconhecemos uma ontologia na qual a prática é a constituidora do fenômeno do roteiro turístico e a base da epistemologia para investigá-lo. Isso é, também, uma contribuição para impulsionar a multiplicidade de vozes que caracterizam o campo de estudo de turismo e a sua contínua transformação (Ren, Pritchard \& Morgan, 2010). Dentro desse campo, sugerimos que os pesquisadores, em seus estudos futuros, e os profissionais do setor pensem o organizar do roteiro como contínuo e fragmentado, compreendendo que a padronização e a predefinição são apenas uma parte de seu organizar. Trata-se de uma ótica que contribui para reconhecer e aproveitar o envolvimento dos turistas e demais praticantes nesse organizar. 


\section{REFERÊNCIAS}

Bispo, M. S. (2012). Aprendizaje colectivo en el uso de la tecnología como práctica en las agencias de viajes: Un abordaje etnometodológico. Estudios y perspectivas em Turismo, 21(6), 1541-1557.

Bispo, M. S. (2016, novembro). Tourism as practice. Annals of Tourism Research, 61, 170-179.

Bispo, M. S., \& Godoy, A. S. (2012). The learning process of the use of technologies as practice: an ethnomethodological approach in travel agencies. Revista Brasileira de Pesquisa em Turismo, 6(2), 160-180.

Cavalcante, E. D. C., \& Bispo, M. S. (2018). A análise etnometodológica do turismo como prática numa orla marítima no Nordeste brasileiro. Organizações \& Sociedade, 25(85), 247-263.

Cavedon, N. R. (1999). O método etnográfico em estudos sobre a cultura organizacional: implicações positivas e negativas. In Anais do 23 Encontro Nacional de Programas de Pós-Graduação em Administração, Foz do Iguaçu, PR.

Cellard, A. (2008). A análise documental. In J. Poupart, J., J. P. Deslauries, L. H. Groulx, A. Laperrièrre, R. Mayer, A. P. Pires (Eds.), A pesquisa qualitativa: enfoques epistemológicos e metodológicos. Petrópolis, RJ: Vozes.

Cisne, R., \& Gastal, S. (2011). Nueva visión sobre los itinerarios turísticos: una contribución a partir de la complejidad. Estudios y Perspectivas en Turismo, 20(6), 1449-1463.

Cohen, E., \& Cohen, S. A. (2012). Current sociological theories and issues in tourism. Annals of Tourism Research, 39(4), 2177-2202.

Creswell, J. W. (2012). Qualitative inquiry and research design: choosing among five approaches. London, UK: SAGE, 2012.

Cutler, S. Q., Carmichael, B., \& Doherty, S. (2014). The Inca Trail experience: does the journey matter? Annals of Tourism Research, 45, 152-166.

Czarniawska, B. (2008). Organizing: how to study it and how to write about it. Qualitative Research in Organizations and Management: An International Journal, 3(1), 4-20.

Dantas, N. G., \& Melo, R. S. (2011). Análise da metodologia de hierarquização de atrativos turísticos como instrumento para elaboração de roteiros turísticos no município de Itabaiana (PB). Caderno Virtual de Turismo, 11(1), 147-163.

Edensor, T. (2001). Performing tourism, staging tourism (re) producing tourist space and practice. Tourist studies, 1(1), 59-81.

Fageda, X., Jiménez, J. L., Perdiguero, J., \& Marrero, K. (2017, agosto). Does market exit of a network airline affect airline prices and frequencies on tourist routes? Tourism Management, 61, 465-471.

Fontana, A., \& Frey, J. H. (2005). The interview: from neutral stance to political involvement. In N. K. Denzin, \& Y. S. Lincoln (Orgs.). The SAGE Handbook of Qualitative Research (3a. ed., pp. 695-727). Thousand Oaks: SAGE Publications.

Gherardi, S. (2009). Introduction: the critical power of the "practice lens". Management Learning, 40(2), 115-128.

Jiang, L., \& Xu, H. (2016). Reading, tourism, and geography consumption in literary places. Tourism Geographies, 18(5), 1-20.
Júlio, A. C., \& Tureta, C. (2018). Transformando lixo em luxo: a materialidade nas práticas da produção carnavalesca. Brazilian Business Review, 15(5), 427-443.

Lamers, M., Duim, R., \& Spaargaren, G. (2017). The relevance of practice theories for tourism research. Annals of Tourism Research, $62,54-63$.

Latour, B. (2005). Reassembling the social: an introduction to actor-network-theory. Oxford, UK: Oxford University Press.

Li, X., Zhou, J., \& Zhao, X. (2016). Travel itinerary problem. Transportation Research Part B, 91, 332-343.

Meira, F. B., \& Meira, M. B. V. (2007). Considerações sobre um campo científico em formação: Bourdieu e a "nova ciência" do turismo. Cadernos EBAPE.BR, 5(4), 1-18, 2007.

Moraes, W. V., \& Emmendoerfer, W. L. (2015). Turismo comunitário e inclusão social: análise do roteiro turístico de base comunitária do Projeto Boas Práticas na Serra do Brigadeiro - MG/Brasil. Anais Brasileiros de Estudos Turísticos, 5(3), 26-35.

Nicolini, D., Gherardi, S., \& Yanow, D. (2003). Introduction: toward a practice-based view of knowing and learning in organizations, In D. Nicolini, S. Gherardi, \& D. Yanow (Orgs.), Knowing in organizations: a practice-based approach (pp. 3-31). London, UK: M. E. Sharpe.

Oppliger, E. A., Fountoura, F. M., Oliveira, A. K. M., Toledo, M. C. B., Silva, M. H. S., \& Guedes, N. M. R. (2016). O potencial turístico para a observação da avifauna em três áreas verdes na cidade de Campo Grande, MS. Revista Brasileira de Pesquisa em Turismo, 10(2), 274-292.

Peng, H., Zhang, J., Liu, Z., \& Yang, L. (2016). Network analysis of tourist flows: a cross-provincial boundary perspective. Tourism Geographies, 18(5), 561-586.

Pimentel, R., \& Nogueira, E. E. S. (2018). Estudos baseados na prática: possibilidades metodológicas para pesquisas em estudos organizacionais. Organizações \& Sociedade, 25(86), 350-370.

Rantala, O., Valtonen, A., \& Markuksela, V. (2011). Materializing tourist weather: ethnography on weather-wise wilderness guiding practices. Journal of Material Culture, 16(3), 285-300.

Reckwitz, A. (2002). Toward a theory of social practices: a development in culturalist theorizing. European Journal of Social Theory, 5(2), 243-263.

Ren, C., Pritchard, A., \& Morgan, N. (2010). Constructing tourism research: a critical inquiry. Annals of Tourism Research, 37(4), 885-904.

Roper, A., \& Hodari, D. (2015, dezembro). Strategy tools: contextual factors impacting use and usefulness. Tourism Management, 51, 1-12.

Sandberg, J., \& Dall'Alba, G. (2009). Returning to practice anew: a life-world perspective. Organization Studies, 30(12), 1349-1368.

Santos, L. L. S., \& Silveira, R. (2015). Por uma epistemologia das práticas organizacionais: a contribuição de Theodore Schatzki. Organizações \& Sociedade, 22(72), 79-98.

Schatzki, T. R. (2001). Introduction: practice theory. In T. R. Schatzki, K. Knorr-Cetina, \& E. Von Savigny (Orgs.), The practice turn in contemporary theory (pp. 10-23). London, UK: Routledge. 
Schatzki, T. R. (2002). What is a social practice? In T. R. Schatzki (Ed.), The site of the social: a philosophical account of the constitution of social life and change (pp. 70-88). Pennsylvania, Philadelphia: Pennsylvania State University.

Schatzki, T. R. (2003). A new societist social ontology. Philosophy of the Social Sciences, 33(2), 174-202.

Schatzki, T. R. (2005). The sites of organizations. Organization Studies, 26(3), 465-484.

Schatzki, T. R. (2006). On organizations as they happen. Organization Studies, 27(12), 1863-1873.

Stone, M. J. (2016). Impact of delays and cancellations on travel from small community airports. Tourism and Hospitality Research, 18(2), 214-228.
Sudiarta, I. N., \& Suardana, I. W. (2016). Tourism destination planning strategy: analysis and implementation of marketing city tour in Bali. Procedia Social and Behavioral Sciences, 227, 664-670.

Tomazzoni, E. L., Dorion, E., \& Zottis, A. (2008). Análise organizacional de destinos turísticos com base nos conceitos de mudança, de incerteza e na teoria do caos: estudo dos exemplos de Gramado e Canela, na Serra Gaúcha. Organizações \& Sociedade, 15(47), 137-154.

Tribe, J. (2010). Tribe, territories and networks in the tourism academy. Annals of Tourism Research, 37(1), 7-33.

Xia, J., Zeephongsekul, P., \& Arrowsmith, C. (2009). Modelling spatio-temporal movement of tourists using finite Markov chains. Mathematics and Computers in Simulation, 79(5), 1544-1553.

Talita Almeida Fernandes ORCID: https://orcid.org/0000-0001-5171-5872

Mestre em Administração pela Universidade Federal do Espírito Santo (UFES). E-mail: fernandes.talitaalmeida@gmail.com

Alfredo Rodrigues Leite da Silva

ORCID: https://orcid.org/0000-0002-5943-1185

Doutor em Administração pela Universidade Federal de Minas Gerais (UFMG); Professor associado do Departamento de Administração da Universidade Federal do Espírito Santo (UFES).E-mail: alfredoufes@gmail.com

Filipe Cabacine Lopes Machado ORCID: https://orcid.org/0000-0002-6152-6079

Mestre em Administração pela Universidade Federal do Espírito Santo (UFES); Professor do Ensino Básico, Técnico e Tecnológico (EBTT) do Instituto Federal do Espírito Santo (IFES). E-mail: filipecabacine@gmail.com 